\title{
Attention deficit/hyperactivity disorder symptoms in indigenous children from the Brazilian Amazon
}

\author{
Paulo Verlaine Borges e Azevêdo', Leonardo Caixeta², \\ Laura Helena Silveira Andrade ${ }^{3}$, Isabel A. Bordin ${ }^{4}$
}

\begin{abstract}
The clinical constructs of attention deficit/hyperactivity disorder (ADHD) have been described in several cultures worldwide. Yet this symptomatic presentation still remains to be assessed in remote population groups. Objective: To explore the possibility of the existence of ADHD symptoms among settlement-dwelling indigenous children of the Karajá ethnic group in the Brazilian Amazon and to estimate the rate of ADHD symptoms among 7-16-year-olds. Method: All parents/caretakers of 7-16-year olds from all $(\mathrm{N}=5)$ most populated indigenous groups were invited to participate, if they were worried about their children emotional/behavioural problems. Fifty three parents spontaneously came for a psychiatric interview (DSM-IV criteria applied), individually conducted at the settlement's health post by a child psychiatrist. Results: The estimated rate of ADHD symptoms in problematic indigenous children aged 7-16 years was $24.5 \%$ (95\% Cl: $13.6-35.4$ ) since 13 out of 53 parents/caretakers reported the classical triad of ADHD symptoms (inattentiveness, hyperactivity, impulsiveness). Conclusion: ADHD is a clinically relevant construct in the Karajá indigenous population, representing a major concern among parents/caretakers of children and adolescents from this ethnic group.
\end{abstract}

Key words: attention deficit disorder with hyperactivity, mental health, child psychiatry, indigenous health.

Sintomas do transtorno de déficit de atenção e hiperatividade em crianças indígenas da Amazônia Brasileira

\section{RESUMO}

Os construtos clínicos do transtorno de déficit de atenção/hiperatividade (TDAH) têm sido descritos em várias culturas ao redor do mundo, entretanto esta apresentação sintomatológica ainda tem sido pouco investigada em grupos populacionais mais isolados. Objetivo: Explorar a possibilidade da existência de sintomas do TDAH entre crianças índias da etnia Karajá na Amazônia Legal Brasileira e estimar a prevalência dos sintomas do TDAH entre aquelas com 7-16 anos de idade. Método: Todos os pais-cuidadores das crianças entre os 7-16 anos de idade, das cinco aldeias mais populosas foram convidados

\section{Correspondence}

Paulo Verlaine Borges e Azevêdo Rua SB 21 Quadra 11 Lote 22 Condomínio Residencial Portal do Sol I Bairro Jardim Sta Bárbara 74884-608 Goiânia G0 - Brasil E-mail: pvbazevedo@gmail.com

Received 12 November 2009

Received in final form 23 December 2009 Accepted 7 January 2010 a participar se houvesse qualquer preocupação acerca de problemas de comportamento e emocionais com suas crianças. Cinqüenta e três pais compareceram espontaneamente para a entrevista psiquiátrica (aplicando-se os critérios do DSM-IV), individualmente conduzida no posto de saúde da aldeia por um psiquiatra infantil. Resultados: A taxa de 
prevalência estimada dos sintomas do TDAH nas crianças entre os 7-16 anos de idade, naquelas que apresentaram problemas foi de 24,5\% (IC 95\% 13,6-35,4), desde que 13 dos 53 pais-cuidadores referiram a tríade sintomatológica clássica do TDAH (desatenção, hiperatividade e impulsividade). Conclusão: O TDAH é um construto clinicamente relevante na população indígena Karajá, representando uma grande preocupação entre os pais ou cuidadores das crianças e adolescentes desse grupo étnico.

Palavras-chave: transtorno de déficit de atenção com hiperatividade, saúde mental, psiquiatria infantil, saúde indígena.

Of the world's entire population, $4 \%$ to $5 \%$ are indigenous representatives (approximately 250 million individuals). The Karajá indigenous group account for a rare part of natives who still live in isolated settlements in remote regions of the Amazon, centre-west Brazil. According to a report from the World Health Organization (WHO) ${ }^{1}$, socioeconomic and cultural aspects can not be dissociated from any eventual mental disorder without the risk of envisaging something which, in fact, does not exist within this type of human population. Epidemiological investigations into mental disorders and behavioural problems within indigenous populations are scarce and even if they do exist, methodological problems give rise to questions regarding their accuracy ${ }^{1}$. The anthropological component thus becomes vital as it tests the validity of western diagnostic categories about different cultures under study ${ }^{2}$.

The study objectives are: to explore the possibility of the existence of symptoms of attention deficit hyperactivity disorder (ADHD) among settlement-dwelling indigenous children of the Karajá ethnic group in the Brazilian Amazon, to estimate the rate of ADHD symptoms among 7-16-year olds (according to parents/caretakers symptoms reports and observation of children during a psychiatric interview), and to generate hypothesis to explain the presence of symptoms suggestive of ADHD.

\section{METHOD}

An experienced child psychiatrist conducted clinical interviews with 53 parents/caretakers (child-rearing adults) of indigenous children from the Karajá ethnic group living in the Bananal Island, in the Legal Amazon, Brazil. All parents/caretakers from the five most populated settlements of the Karajá ethnic group (10 settlements in total) were invited to participate in the study. Eligibility criteria included: having at least one child aged 7-16 years, and having worries or complaints about the behaviour of their children. All parents/caretakers from the five selected settlements (Santa Isabel do Morro, Fontoura, São Domingos, JK and Wataú) with worries/complaints regarding their children's mental health that spontaneously came for a psychiatric interview $(\mathrm{N}=53)$ accepted to participate in the study. From an estimated popula- tion of 457 Karajá children aged 7-16 years living in the selected five settlements, 53 children (one child per family) representing $11.6 \%$ of children in this age range were included in the study.

The mental health of children was assessed based on spontaneous reports by family members (parents/caretakers). Parents/caretakers were asked to take their problematic children to psychiatric examination (parents/caretakers were interviewed, and children were observed regarding their behaviour). In order to elicit subjective reports of the main problems they suffered with regard to their youngsters' behaviours, interviews were individually conducted at the settlements' health post by a child psychiatrist with the help of a native health worker proficient in the local language and Portuguese. The interviews were preceded by statements as: 'Tell us about situations related to the behaviour(s) of your child which are creating worries for the family, school, community and/ or your child.' Verbatim accounts of reported problems were recorded. Open-ended questions were asked to assess frequency and impairment due to symptoms and behaviours reported: 'Do these behaviours occur very frequently or sporadically?' 'Have these behaviors interfered with learning or class work?' 'Have these difficulties put a burden on the child or the family as a whole?' 'Do they affect personal and social relations?' 'Do they occur in more than one environment (home and school, for example)?' 'Did they start before 7 years of age?' 'Do they present additional behavioural problems?' Assessment of family psychiatric history and child psychomotor development were also performed.

The research was approved by the ethic committee of Universidade Federal de Goiás (UFG) and by the Brazilian Foundation for the Protection of Indigenous Populations (FUNAI). Written informed consent was obtained before each interview. Children with symptoms suggestive of mental disorders were referred to specialized medical-psychological treatment.

\section{RESULTS}

Of the total of 53 children evaluated (32 males and 21 females), no one was free of psychiatric disorders and 13 
presented symptoms and behaviours coherent with the construct of ADHD, with hyperactivity as the main complaint. Parents/caretakers who reported ADHD symptoms also mentioned an impaired functioning of their children when considering family relationships and school performance. The rate of ADHD symptoms among 7-16year olds with emotional/behavioural problems from the five selected settlements was $24.5 \%$ (95\% CI: 13.6-35.4), since 13 out of 53 children presented the classical triad of ADHD symptoms (inattentiveness, hyperactivity, impulsiveness). Rates of ADHD symptoms for disordered boys [21.9\% (95\% CI 8.5-35.3)] and disordered girls [28.6\% (95\% CI 10.2-46.9)] did not differ ( $\mathrm{p}=0.58$ ).

One case description is presented below to illustrate parental reports suggestive of ADHD symptoms in the studied population. In addition, parental alcohol and/or drug abuse and domestic violence are examples of environmental factors frequently reported by parents/caretakers of the studied sample.

\section{Case: boy, 7 years old}

The mother reports that since the first year of life, the child has been quite restless, disobedient and does not seem to listen when talked to. The child shows no respect for anybody. He can not sit still at school for not even an instant and he is also "slow" to learn leading to several school complaints regarding his deficient learning, compared to his classmates. He blinks excessively and has a restless sleep and reduced appetite. He was born after a full 9-month problem-free pregnancy. No developmental delays. Vaccinations completed. No cranial-encephalic traumas, central nervous system (CNS) infections, epileptic seizures or chronic medical problems. In mother's opinion, he is intelligent and affectionate. The mother smoked 20 cigarettes a day during pregnancy.

\section{DISCUSSION}

Psychiatric clinical interviews with parents/caretakers revealed that $\mathrm{ADHD}$-related symptoms represent a major concern regarding indigenous children and adolescents' mental health in the Karajá ethnic group. The classical triad of ADHD symptoms, namely inattentiveness, hyperactivity and impulsiveness ${ }^{3}$ was spontaneously reported by 24.5\% (95\% CI: 13.6-35.4) of all participant parents/caretakers that were worried about their children's emotional/ behavioural problems in the five selected settlements.

Estimates of ADHD prevalence rates for children and adolescents vary worldwide depending on study methods such as sample characteristics (age of subjects, percentage of males, general population or clinical sample), and instruments applied (screening or diagnostic interview, edition of $\mathrm{DSM}^{4}$ criteria, requirement of impairment for diagnosis, parental report or combined informants) $)^{5-8}$. Therefore, our findings must be compared to results of studies that used similar methods. However, one may hypothesize that not all indigenous parents/ caretakers worried about their children's mental health came to the health post to be interviewed. In this case, the prevalence rates of ADHD symptoms and of emotional/behavioural problems overall among Karajá children would be even higher than the rate expected in the Brazilian general population. This fact is in accordance with international studies. For instance, in Canada, Baydala et al. ${ }^{9}$ found a high number of Aboriginal children with symptoms associated with ADHD, which was significantly higher than the number expected based on prevalence rates in the general population. According to the authors, these findings suggest either a high prevalence of ADHD in Aboriginal children or unique learning and behavioral patterns in Aboriginal children that may erroneously lead to a diagnosis of ADHD if screening questionnaires are used. Considering our findings, we agree with the hypothesis that indigenous children may present high rates of ADHD symptoms, but we disagree that it may represent a unique learning and behavioral patterns in this ethnic group. In our study, parents/caretakers spontaneously reported inattentiveness, hyperactivity and impulsiveness in their children with the perception of the existence of a disorder or disturbance since these behaviours were not expected in normal indigenous children from their community. However, what is not clear is the role of environmental factors such as domestic violence, and substance abuse by parents, also frequent in the studied community. According to Isaacs ${ }^{10}$, it is important to consider variations in ADHD symptoms due to environmental context, in terms of the influence of the child's family and school, since the incidence of ADHD increases with social disadvantage.

This is the first description of ADHD related symptoms in indigenous children from the Brazilian Amazon. However, there are some important study limitations that must be recognized. First, the sample was restricted to children and adolescents whose parents believed had behavioral problems, a sample characteristic that may have overestimated the prevalence of ADHD symptoms. Second, the assessment of ADHD symptoms was based on parental reports and child clinical observations, but did not include teachers as informants. Finally, DSM-IV diagnoses were made without using a structured psychiatric interview since there is no valid version in the local language.

In conclusion, ADHD symptoms reported by parents/ caretakers of children from the Karaja ethnic group in the Brazilian Amazon are in accordance with DSM-IV ${ }^{5}$ criteria, and support the transcultural validation of essential symptoms of the psychiatric diagnostic category ADHD. ADHD symptoms represent a major concern for indige- 
nous parents/caretakers. Because ADHD symptoms tend to increase with social disadvantage, family stressors frequently noted in the studied sample (e.g. parental alcohol/drug abuse, domestic violence) may have contributed to the high rate observed.

\section{REFERENCES}

1. Cohen A. The mental health of indigenous peoples: an international overview. Geneva: World Health Organization (WHO), 1999.

2. Lewis-Fernández R, Kleinman A. Cultural psychiatry: theoretical, clinical, and research issues. Psychiatr Clin North Am 1995;18:433-448.

3. Rohde LA, Barbosa G, Tramontina S, Polanczyk G. Transtorno de déficit de atenção/hiperatividade. Rev Bras Psiquiatr 2000;22(Supl 2):S7-S11.
4. American Psychiatric Association. Diagnostic and statistical manual of mental disorders. $4^{\text {th }}$ Ed. Washington (DC): American Psychiatric Association, 1994.

5. Faraone SV, Sergeant J, Gillberg C, Biederman J. The worldwide prevalence of ADHD: is it an American condition? World Psychiatry 2003; 2:104-113.

6. Polanczyk G, Rohde LA. Epidemiology of attention-deficit/hyperactivity disorder across the lifespan. Curr Opin Psychiatry 2007;20:386-392.

7. Polanczyk G, Lima MS, Horta BL, Rohde LA. The worldwide prevalence of ADHD: a systematic review and metaregression analysis. Am J Psychiatry 2007;164:942-948

8. Polanczyk G, Jensen P. Epidemiologic considerations in attention deficit hyperactivity disorder: a review and update. Child Adolesc Psychiatr Clin N Am 2008;17:245-260.

9. Baydala L, Sherman J, Rasmussen C, Wikman E, Janzen H. ADHD characteristics in Canadian Aboriginal children. J Atten Disord 2006; 9:642-647.

10. Isaacs D. Attention-deficit/hyperactivity disorder: are we medicating for social disadvantage?. J Paediatr Child Health 2006;42:544-547. 